\title{
Community-acquired methicillin-resistant Staphylococcus aureus infections: hospitalization and case fatality risk in 10 pediatric facilities in Argentina
}

\author{
Ángela Gentile, M.D. ${ }^{a}$, Julia Bakir, M.D. ${ }^{a}$, Gabriela Ensinck, M.D. ${ }^{b}$, \\ Aldo Cancellara, M.D. ${ }^{c}$, Enrique V. Casanueva, M.D. ${ }^{d}$, Verónica Firpo, M.D. ${ }^{e}$, \\ Martín Caruso, M.D. ${ }^{f}$, María F. Lución, M.D. ${ }^{a}$, Alejandro Santillán Iturres, M.D. ${ }^{g}$, \\ Fabiana Molina, M.D. ${ }^{h}$, Héctor J. Abate, M.D. ${ }^{i}$, Andrea Gajo Gane, M.D. ${ }^{j}$, \\ Santiago López Papucci, M.D. ${ }^{b}$ and Staphylococcus aureus Task Force*
}

\section{ABSTRACT}

Introduction. Community-acquired methicillinresistant Staphylococcus aureus (CA-MRSA) infections are prevalent both in Argentina and worldwide, and they may have a severe clinical course.

Objectives: To estimate the hospitalization rate and case fatality risk factors of CA-MRSA infection.

Methods. Cross-sectional, analytical study. All patients $\leq 15$ years old with community-acquired Staphylococcus aureus (CA-SA) infections admitted to 10 pediatric facilities between January 2012 and December 2014 were included.

Results. Out of 1141 patients with CA-SA, 904 (79.2\%) had CA-MRSA. The rate of hospitalization of CA-MRSA cases (per 10000 discharges) among patients $<5$ years old was 27.6 in 2012, 35.2 in 2013, and 42.7 in 2014 ( $p=0.0002)$. The 2-4-year-old group was the most affected one: $32.2,49.4$, and 54.4, respectively $(\mathrm{p}=0.0057)$. The clinical presentations included skin and soft tissue infections: $66.2 \%$, pneumonia: $11.5 \%$, sepsis/bacteremia: $8.5 \%$, osteomyelitis: $5.5 \%$, arthritis: $5.2 \%$, psoas abscess: $1.0 \%$, pericarditis/ endocarditis: $0.8 \%$, meningitis: $0.6 \%$, and other: $0.7 \%$. In terms of antibiotic resistance, $11.1 \%$ had resistance to erythromycin; $8.4 \%$, to gentamicin; and $0.6 \%$, to trimethoprim-sulfamethoxazole. All strains were susceptible to vancomycin. The case fatality rate was $2.2 \%$ and associated risk factors were (odds ratio [95\% confidence interval]) age $\geq 8$ years $(2.78,1.05-7.37)$, pneumonia $(6.37,2.37$ 17.09), meningitis (19.53,2.40-127.87), and sepsis / bacteremia (39.65, 11.94-145.55).

Conclusions. The rate of CA-MRSA infection was high; the rate of hospitalization increased in the 2013-2014 period; the 2-4-year-old group was the most affected one. A higher case fatality risk was observed among patients $\geq 8$ years old and those with the clinical presentations of pneumonia, meningitis, and sepsis.
Key words: staphylococcal infections, fatality, risk factors, pediatrics.

http:/ / dx.doi.org/10.5546/ aap.2018.eng.e47

To cite: Gentile Á, Bakir J, Ensinck G, et al Community-acquired methicillin-resistant Staphylococcus aureus infections: hospitalization and case fatality risk in 10 pediatric facilities in Argentina. Arch Argent Pediatr 2018;116(1):e47-e53.

\section{Glossary}

CA-MRSA: community-acquired methicillin-resistant Staphylococcus aureus

CA-SA: community-acquired

Staphylococcus aureus

$\mathrm{h}$ : hours

HA-MRSA: hospital-acquired methicillin-resistant Staphylococcus aureus

MRSA: methicillin-resistant

Staphylococcus aureus

MSSA: methicillin-susceptible

Staphylococcus aureus

OR: odds ratio

PCV13: 13-valent pneumococcal conjugate vaccine

PVL: Panton-Valentine leukocidin SEL: socio-economic level SSTI: skin and soft tissue infection SA: Staphylococcus aureus TMP-SMZ: trimethoprimsulfamethoxazole

Funding:

None

Conflict of interest:

None.

Received: 3-21-2017 Accepted: 8-29-2017
*Staphylococcus aureus Task Force: Nanci Míguez, M.D., B.S., Ivana Morales, M.D., Laura Miño, M.D., Macarena Uranga, M.D., Norma Fernández, M.D., María R. Miranda, M.D., Patricia Carrizo Herrera, M.D., Pablo Scoleri, M.D., María R. Baroni, Biochemist, and Carolina Aguirre, M.D. 


\section{INTRODUCTION}

Staphylococcus aureus (SA) is a widely distributed microorganism in this setting. It colonizes the skin and mucous membranes of 30$50 \%$ of healthy children and adults. It may cause a broad range of infections, from mild skin and soft tissue infections (SSTIs) to invasive ones, such as pneumonia, bacteremia, and sepsis. ${ }^{1}$

Years after the introduction of methicillin in 1959, methicillin-resistant SA (MRSA) outbreaks were reported. ${ }^{2}$ Initially, MRSA infections occurred in the hospital setting (HA-MRSA) or in association with health care. ${ }^{3}$

In the 1990s, reports started referring to patients colonized by or infected with communityacquired MRSA (CA-MRSA) strains in different areas of the United States and worldwide. ${ }^{4,5}$ Outbreaks were documented in communities characterized by over-crowding, prisoners, recruits, children attending daycare centers, contact sport athletes, men who have sex with men, and injection drug users. Initially, they had SSTIs and some patients progressed to invasive disease. ${ }^{6,7}$

In Argentina, Paganini et al. identified SSTIs in a children's hospital around $2004^{8}$ and then reported, in a multicenter study, CA-MRSA rates above $60 \%$ in most facilities. ${ }^{9}$ Other more recent Argentine studies conducted using different methodologies have reported $55 \%$ rates in 66 pediatric and adult health care facilities in November $2009,{ }^{10}$ and a $65 \%$ resistance in community-acquired SA (CA-SA) bacteremias. ${ }^{11}$

CA-MRSA strains showed an antibiotic susceptibility pattern different from those acquired in the community. CA-MRSA strains were, in general, multi-drug resistant, whereas CA strains were only resistant to methicillin, variably susceptible to erythromycin / clindamycin, and highly susceptible to trimethoprim-sulfamethoxazole (TMP-SMZ). ${ }^{4}$

Although genes coding for resistance to methicillin in hospital and community strains are the same, the staphylococcal cassette chromosome into which these genes are included is different, thus indicating that community strains do not distribute hospital strains. ${ }^{12,13}$ In addition, a cytotoxin called Panton-Valentine leukocidin (PVL) present in CA-MRSA strains and in some methicillin-susceptible SA (MSSA) strains was associated with SSTIs, ${ }^{4,14}$ invasiveness, osteomyelitis, necrotizing pneumonia, and poor prognosis. ${ }^{4,14-18}$ However, more recently, PVL's role as a virulence determinant has been discussed. ${ }^{19}$
The objectives of this study were to estimate the rate of hospitalization for CA-MRSA infection, describe the patients' clinical, epidemiological, and microbiological characteristics, and analyze case fatality risk factors in selected facilities that represented different regions of Argentina.

\section{POPULATION AND METHODS}

Design: Epidemiological, observational, crosssectional study with prospective data capture.

Study sites: Ten pediatric facilities participated (by region).

a. Northwest: Hospital del Niño Jesús (Tucumán), Hospital de Niños H. Quintana (Jujuy), Hospital de Niños E. Perón (Catamarca).

b. Northeast: Hospital Pediátrico J. Pablo II (Corrientes).

c. Cuyo: Hospital Pediátrico H. Notti (Mendoza).

d. Central Region: Hospital de Niños Víctor J. Vilela (Rosario), Hospital de Niños O. Alassia (Santa Fe).

e. Buenos Aires: Hospital de Niños de San Justo (Buenos Aires), Hospital de Niños P. de Elizalde (Autonomous City of Buenos Aires [CABA]), Hospital de Niños R. Gutiérrez (CABA).

Every site had the human and logistic resources and an adequate infrastructure to cater for hospitalized patients and perform imaging and bacteriological tests.

Inclusion criteria: All patients $\leq 15$ years old with CA-SA infection, hospitalized in any of the 10 pediatric facilities between January 2012 and December 2014 were included.

Patients were admitted through the epidemiological surveillance system which is active in hospitalization units. Subsequently, a specially-designed card was completed with the following data: participating site, patient ID code, date of hospitalization, demographic data, clinical and epidemiological outcome measures (age, sex, immunization status, number of household members, number of people rooming together, socio-economic level, underlying diseases, nutritional status, secondhand smoking, prior hospitalizations in the past year, prior antibiotic therapy in the past 3 months, clinical presentations, bacteriological cultures and antibiotic susceptibility, isolation sites, antibiotic therapy, and clinical course [complications and status on discharge]).

In addition, a sheet was used to record the monthly number of CA-SA and CA-MRSA 
infections and the total number of hospital discharges.

\section{Definitions}

CA-SA infection case: Any patient with SA isolated from a normally sterile site in an outpatient manner, within the first 48 hours (h) of admission to the hospital or after $48 \mathrm{~h}$ of hospitalization, but with clear clinical evidence suggesting that the infection was acquired in the community (e.g., a patient without prior hospitalization admitted with osteomyelitis and who had a surgical drainage done $48 \mathrm{~h}$ later, where SA developed). ${ }^{4,20}$

CA-MRSA infection case: The same as in case a) with identification of MRSA.

The socio-economic level (SEL) was defined using the Graffar-Méndez Castellanos test ${ }^{21}$, and the classification was simplified into high (stratum I), middle (strata II and III), and low (strata IV and V) SEL.

Underlying diseases included conditions that involved the skin (varicella, burn wound, trauma injury, skin disease, perforation, other), chronic pulmonary diseases (chronic obstructive pulmonary disease, cystic fibrosis, emphysema, and asthma), cardiovascular diseases (congenital heart defect, congestive heart failure, cardiomyopathy, hypertensive heart disease, pulmonary hypertension, valvular heart defect, arrhythmia), liver and kidney diseases, metabolic disorders (such as diabetes), neurological or neurodevelopmental disorders (cerebral palsy, seizures, stroke, mental retardation, spinal cord injury or muscle dystrophy), hematological disorders (anemia, functional or anatomical asplenia), chromosomal and genetic disorders, drug- or disease-induced immunosuppression (e.g., human immunodeficiency virus [HIV], cancer or long-term corticosteroid therapy), and complement deficiency.

Nutritional status was diagnosed based on age, weight, and height. The 2013 Guidelines of the Argentine Society of Pediatrics ${ }^{22}$ were used to define obesity (Z-score $>2$ ) and malnutrition (Z-score $<2$ or a weight for age percentile $<3$ ).

Second-hand smoking (World Health Organization criterion) was defined as the involuntary exposure to environmental tobacco smoke for more than 15 minutes per day, more than once a week.

SA was identified using the conventional methods established in each hospital's bacteriology laboratory. Antibiograms were interpreted according to the currently valid Clinical and Laboratory Standards Institute (CLSI). ${ }^{23}$

\section{Ethical considerations}

Information was stored in a restricted access database. Personal data were recorded using an alphanumeric code so that investigators were kept blinded to patient identification.

The study was approved by the Research and Ethics Committee of the corresponding hospitals.

\section{Statistical analysis}

Results were expressed as mean \pm standard deviation, and the median (range) value was used for the age outcome measure. Categorical outcome measures were described in terms of percentage and analyzed using a $\chi^{2}$ test with Yates' correction.

Initially, the following potential fatality risk factors were identified: clinical and epidemiological outcome measures and clinical presentations; the measure of association was odds ratio (OR) with a $95 \%$ confidence interval (CI).

Finally, a logistic regression was done to establish independent outcome measures; independent outcome measures were included manually if their $p$ value was 0.10 or less in the univariate analysis.

A value of $\mathrm{p}<0.05$ was considered significant.

The annual rate of hospitalization for CAMRSA infection was estimated by dividing the total number of cases of CA-MRSA infections by the total number of discharges per year and per age group, multiplied by 10000 .

The Epi Info version 7 (CDC, Atlanta) was used to make a descriptive and univariate analysis and to estimate the $\chi^{2}$ test for the trend of the hospitalization rate. The SPSS Statistics, version 17.0, was used for the multivariate analysis.

\section{RESULTS}

Out of a total of 252050 patients hospitalized in the 10 facilities, $1141(0.45 \%)$ had a CA-SA infection; of these, $904(79.2 \%)$ corresponded to CA-MRSA. Tables 1 and 2 show the annual rates of hospitalization of patients with CA-SA and CAMRSA by age group, respectively.

Among the 904 patients with CA-MRSA infection, their mean age was 63.7 months (standard deviation: 55.5); their median age, 44.0 months (range: 1-190); 33.5\% were younger than 2 years; and $61.5 \%$ were boys. Also, $51.4 \%$ had an 
immunization card; of these, $90.5 \%$ had received the Haemophilus influenzae type $\mathrm{b}$ vaccine and $66.3 \%(134 / 202)$ of patients $<24$ months old had received the 13-valent pneumococcal conjugate vaccine (PCV13). In terms of socio-economic level, $33.1 \%$ corresponded to a middle SEL and $65.3 \%$, a low SEL. The number of people sharing the household was recorded in 830 cases and was $>5$ in $49.6 \%$ of them; likewise, the number of people rooming together was $>3$ in $37.2 \%$ (294/790). An underlying disease was detected in $35.0 \%$ (316/904) of cases (96 had more than one disease), which were the following, by order of frequency: chronic respiratory disease $(33.5 \%)$, skin disease $(20.9 \%)$, anemia $(19.7 \%)$, neurological disease $(8.3 \%)$, cardiovascular disease $(2.9 \%)$, genetic disorder (1.7\%), renal disease or metabolic disorder $(1.5 \%)$, liver disease $(0.5 \%)$, malnutrition $(4.3 \%)$, obesity $(2.6 \%)$, immunosuppression $(4.1 \%)$. Also, $4.2 \%$ of patients had a history of prematurity; $19.2 \%$, of second-hand smoking; $14.7 \%$, of prior hospitalizations in the past year; and $7.7 \%$, of prior antibiotic therapy in the past 3 months.

Four patients had mixed infections: 3 had CA-MRSA and Haemophilus influenzae type $b$ and 1 had CA-MRSA and group A beta-hemolytic Streptococcus.
The clinical presentations are described in Table 3; combined presentations were observed in 227 patients.

Among patients with SSTIs, 60.2\% (451/749) did not have health care-related predisposing factors (an underlying disease or a history of hospitalization in the past year). In addition, 6 out of the 7 patients with meningitis were previously healthy individuals.

Table 3. Clinical presentations of patients with communityacquired methicillin-resistant Staphylococcus aureus infections in 10 hospital facilities, Argentina, 2012-2014

\begin{tabular}{|c|c|c|}
\hline Clinical presentation & $\mathbf{N}$ & $\%$ \\
\hline Skin and soft tissue infection* & 749 & 66.2 \\
\hline Pneumonia & 130 & 11.5 \\
\hline Sepsis/bacteremia & 97 & 8.5 \\
\hline Osteomyelitis & 65 & 5.5 \\
\hline Arthritis & 92 & 5.2 \\
\hline Psoas abscess & 11 & 1.0 \\
\hline Pericarditis/endocarditis & 9 & 0.8 \\
\hline Meningitis & 7 & 0.6 \\
\hline Renal abscess & 2 & 0.2 \\
\hline Liver abscess & 2 & 0.2 \\
\hline Peritonitis & 2 & 0.2 \\
\hline \multirow[t]{2}{*}{ Orchiditis } & 1 & 0.1 \\
\hline & 1131 & 100.0 \\
\hline
\end{tabular}

* 27 cases of myositis and 4 cases of fasciitis.

TABLE 1. Hospitalization rates of patients with community-acquired Staphylococcus aureus infection by age group in 10 hospital facilities, Argentina, 2012-2014

\begin{tabular}{|c|c|c|c|c|c|c|c|c|c|c|}
\hline \multirow[t]{2}{*}{ Age group } & \multicolumn{3}{|c|}{2012} & \multicolumn{3}{|c|}{2013} & \multicolumn{3}{|c|}{2014} & \multirow{2}{*}{$\begin{array}{c}\begin{array}{c}\text { Statistical } \\
\text { significance }\end{array} \\
p\end{array}$} \\
\hline & Discharges & $\mathbf{n}$ & $\begin{array}{c}\text { Rate per } \\
10000\end{array}$ & Discharges & $\mathbf{n}$ & $\begin{array}{c}\text { Rate per } \\
10000\end{array}$ & Discharges & $\mathbf{n}$ & $\begin{array}{c}\text { Rate per } \\
10000\end{array}$ & \\
\hline 0-23 months old & 35979 & 112 & 31.1 & 32029 & 134 & 41.8 & 32787 & 145 & 44.2 & 0.0126 \\
\hline 24-59 months old & 17990 & 77 & 42.8 & 15987 & 97 & 60.7 & 15447 & 95 & 61.5 & 0.0291 \\
\hline$<5$ years old & 53969 & 189 & 35.0 & 48016 & 231 & 48.1 & 48234 & 240 & 49.8 & 0.0004 \\
\hline 5-15 years old & 35980 & 128 & 35.6 & 32460 & 167 & 51.4 & 33391 & 186 & 55.7 & 0.0002 \\
\hline
\end{tabular}

TABLE 2. Hospitalization rates of patients with community-acquired methicillin-resistant Staphylococcus aureus infections by age group in 10 hospital facilities, Argentina, 2012-2014

\begin{tabular}{|c|c|c|c|c|c|c|c|c|c|c|}
\hline \multirow[t]{2}{*}{ Age group } & \multicolumn{3}{|c|}{2012} & \multicolumn{3}{|c|}{2013} & \multicolumn{3}{|c|}{2014} & \multirow{2}{*}{$\begin{array}{c}\begin{array}{c}\text { Statistical } \\
\text { significance }\end{array} \\
p\end{array}$} \\
\hline & Discharges & $\mathbf{n}$ & $\begin{array}{c}\text { Rate per } \\
10000\end{array}$ & Discharges & $\mathbf{n}$ & $\begin{array}{c}\text { Rate per } \\
10000\end{array}$ & Discharges & $\mathbf{n}$ & $\begin{array}{c}\text { Rate per } \\
10000\end{array}$ & \\
\hline 0-23 months old & 35979 & 91 & 25.3 & 32029 & 90 & 28.1 & 32787 & 122 & 37.2 & 0.0127 \\
\hline 24-59 months old & 17990 & 58 & 32.2 & 15987 & 79 & 49.4 & 15447 & 84 & 54.4 & 0.0057 \\
\hline$<5$ years old & 53969 & 149 & 27.6 & 48016 & 169 & 35.2 & 48234 & 206 & 42.7 & 0.0002 \\
\hline 5-15 years old & 35980 & 99 & 27.5 & 32460 & 125 & 38.5 & 33391 & 156 & 46.7 & 0.0001 \\
\hline
\end{tabular}


The microbiological diagnosis was done based on 1003 specimens: skin/soft tissue $(67.4 \%)$, blood $(16.8 \%)$, pleural fluid $(8.0 \%)$, joint fluid $(4.3 \%)$, bone $(2.4 \%)$, cerebrospinal fluid (CSF) $(0.6 \%)$, other $(0.5 \%)$. Figure 1 describes the antibiotic resistance of CA-MRSA strains.

The overall case fatality rate was $2.2 \%(20 / 904)$ and associated risk factors were age $\geq 8$ years and the clinical presentations of pneumonia, meningitis, and sepsis/bacteremia (Table 4). The independent predictor of fatality was the clinical manifestation of sepsis/bacteremia (OR: 44.07, 12.07-160.87).

Severe soft tissue infections (fasciitis and myositis) and clinical and epidemiological outcome measures, such as sex, immunization status, socio-economic level, number of people sharing the household, number of people rooming together, underlying disease, prematurity, second-hand smoking, prior hospitalizations in the past year, and prior antibiotic therapy in the past 3 months, were not associated with a higher fatality rate caused by CA-MRSA infection.

\section{DISCUSSION}

CA-MRSA infections are prevalent in Argentina and in several other countries worldwide $\mathrm{e}^{4,5,8,9}$ and may have a severe clinical course. . $^{15-18}$

At present, it has been recognized that these infections occur in three specific groups: hospital-acquired, community-acquired in patients with health care-related predisposing factors, and community-acquired in patients without predisposing factors. ${ }^{24,25}$ This study did not analyze the first group but the two other categories as a whole.

In our study, community-acquired methicillin resistance was almost $80 \%$, higher than that reported in other studies conducted in Argentina and mentioned here. Such increase may be attributed to methodological differences in patient inclusion in the different studies. ${ }^{8-11}$

Likewise, the rate of hospitalization for CAMRSA infections was observed to increase over the 3 years of the study. Such findings may be explained by a basically ecological phenomenon: nasal colonization by SA may be higher in children who have received the pneumococcal conjugate vaccine, probably due to competence between the vaccine and SA. ${ }^{26,27}$ However, in our study, only $66 \%$ of patients $<24$ months old had completed their PCV13 immunization. In addition, the highest rates of hospitalization for CA-MRSA infection were observed in schoolchildren, who were generally described as the most affected ones ${ }^{28}$ and who

TABLE 4. Risk factors associated with case fatality caused by community-acquired methicillin-resistant Staphylococcus aureus infection in 10 hospital facilities, Argentina, 20122014

\begin{tabular}{|c|c|c|c|}
\hline \multirow[t]{2}{*}{ Risk factor } & \multicolumn{2}{|c|}{ Case fatality rate } & \multirow{2}{*}{ OR $(95 \% \mathrm{CI})$} \\
\hline & & $\%$ & \\
\hline Sepsis/bacteremia & $16 / 97$ & 16.5 & $39.65(11.94-145.55)$ \\
\hline Meningitis & $2 / 7$ & 28.6 & $19.53(2.40-127.87)$ \\
\hline Pneumonia & $10 / 130$ & 7.7 & $6.37(2.37-17.09)$ \\
\hline Age $\geq 8$ years old & $10 / 244$ & 4.1 & $2.78(1.05-7.37)$ \\
\hline
\end{tabular}

OR: odds ratio; CI: confidence interval.

FIGURE 1. Antibiotic resistance of community-acquired methicillin-resistant Staphylococcus aureus strains in 10 hospital facilities, Argentina, 2012-2014

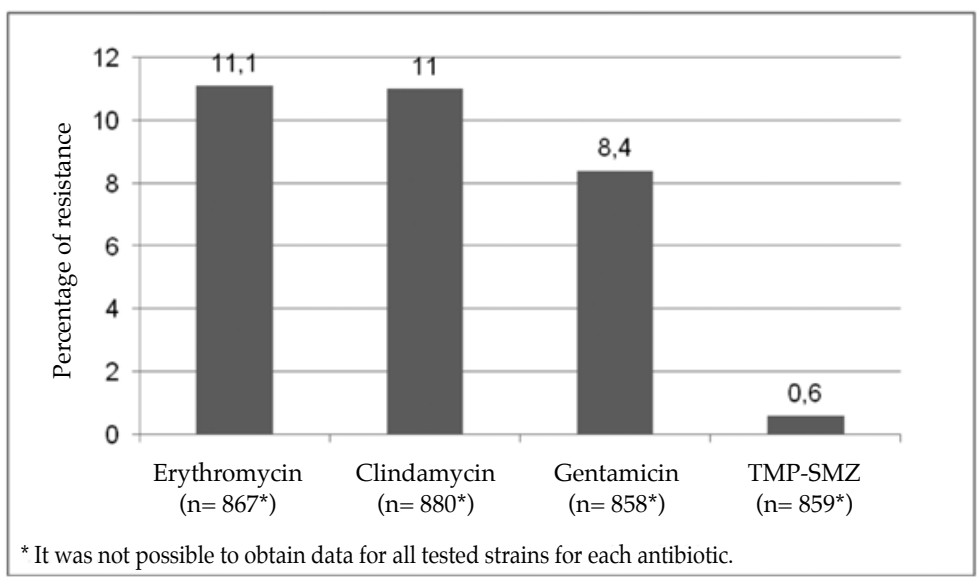


had not received the PCV13 according to the immunization schedule. ${ }^{29}$

A relationship was also described between nasal colonization by SA and amoxicillin/ clavulanic acid treatment in the prior 3 months. ${ }^{30}$ According to our data, $7.7 \%$ of patients had a history of antibiotic therapy in the past 3 months.

CA-MRSA infection occurred mainly among the poorest social strata $(65 \%)$ and in the population living in over-crowding conditions (50\%), as described in the bibliography. ${ }^{28}$ Several studies have also described prior colonization by SA in the patient or the people sharing the household in different body surface areas as a risk factor for SA infection, ${ }^{31}$ which could be favored in over-crowding conditions.

CA-MRSA infection was observed in $42 \%$ of patients with health care-related predisposing factors, such as prior hospitalizations in the past year (15\%) and / or an underlying disease (35\%). The most common underlying diseases were respiratory conditions, as observed in the general pediatric population, followed by skin diseases, such as varicella, burn injuries, bites, etc. Undoubtedly, skin diseases disrupt the skin barrier and favor SA colonization and infection. ${ }^{4,31}$

Second-hand smoking was observed in almost $20 \%$ of patients, so it may be considered a risk factor of the most common underlying disease in the studied population, i.e., respiratory disease. ${ }^{32}$

CA-MRSA infection predominated among healthy children with almost $60 \%$ of events, and the most common clinical presentation was SSTI. This was followed by invasive disease, such as pneumonia, sepsis/bacteremia, and osteoarticular infections. Such locations, by order of frequency, are consistent with what has been published by different authors, both at a national and an international level, given that SSTIs account for $60-90 \%$ of these infections. ${ }^{4,20,25}$ Four patients had mixed infections combined with Haemophilus influenzae type $\mathrm{b}$ and group A beta-hemolytic Streptococcus.

Prior national publications have reported variable antibiotic susceptibility rates for CAMRSA strains. ${ }^{8-11,25}$ In our study, although it included patients with CA-MRSA infection and health care-related predisposing factors, the level of clindamycin and TMP-SMZ susceptibility was acceptable; in addition, all strains were susceptible to vancomycin. These data help to guide pediatricians in the implementation of the initial empirical treatment in the different clinical presentations; clindamycin and TMP-SMZ are still useful antibiotics, especially for the treatment of patients with SSTIs, and vancomycin is reserved for children with severe CA-MRSA infections, such as bacteremia, sepsis, and endocarditis.

The $2 \%$ case fatality rate was similar to that reported in the national publications mentioned here. In addition, risk factors associated with fatality, such as age $\geq 8$ years and the clinical presentations of sepsis/bacteremia, meningitis, and pneumonia, were similar to those reported in other studies. ${ }^{4,33-35}$

It is worth noting that the presence of predisposing factors, sex, and severe soft tissue infections (fasciitis and myositis) were not associated with a higher case fatality rate.

On the one side, the strength of this study is that of all multicenter studies, i.e., they are as close as possible to the country's reality and include reference hospitals that offer primary, secondary, and tertiary health care services in different regions. On the other side, the weakness inherent to this type of study is that not all regions are represented. And, although facilities work with the same methodology, they are not exempt from institutional differences that may sometimes bias some of the studied outcome measures, especially clinical or microbiological ones.

\section{CONCLUSIONS}

The rate of infections caused by CA-MRSA in children was high; the prevalent clinical source was SSTI; and the higher rate of hospitalization was observed among children aged 2-4 years.

Clindamycin resistance was lower than $15 \%$, so it may be used in the case of a suspected infection in children.

The case fatality rate was $2 \%$. Patients $\geq$ 8 years old and the clinical presentations of pneumonia, meningitis, and sepsis accounted for a higher risk.

\section{REFERENCES}

1. American Academy of Pediatrics. Staphylococcal Infections. In: Kimberlin DW, Brady MT, Jackson MA, Long SS, eds. Red Book. 2015 Report of the Committee on Infectious Diseases 30thed. Elk Grove Village, IL: American Academy of Pediatrics; 2015.Pages.715-32.

2. Benner EJ, Kayser FH. Growing clinical significance of methicillin-resistant Staphylococcus aureus. Lancet 1968;2(7571):741-4.

3. Thompson RL, Cabezudo I, Wenzel RP. Epidemiology of nosocomial infections caused by methicillin-resistant Staphylococcus aureus. Ann Intern Med 1982;97(3):309-17.

4. Kaplan SL, Hulten KG, González BE, et al. Three-year surveillance of community-acquired Staphylococcus aureus infections in children. Clin Infect Dis 2005;40(12):1785-91. 
5. Galiana Villar A. Infección por Staphylococcus aureus meticilino resistente adquirido en la comunidad. Arch Pediatr Urug 2003;74(1):26-9.

6. Centers for Disease Control and Prevention. Outbreaks of community-associated methicillin-resistant Staphylococcus aureus skin infections. Los Angeles County, California 20022003. MMWR Morb Mortal Wkly Rep. 2003;52(5):88.

7. Shahin R, Johnson I, Jamieson F, et al. Methicillin-resistant Staphylococcus aureus carriage in a child care center following a case of disease. Arch Pediatr Adolesc Med 1999;153(8):864-8.

8. Paganini H, Verdaguer V, Rodríguez AC, et al. Infecciones causadas por Staphylococcus aureus resistentes a la meticilina en niños provenientes de la comunidad en niños de la Argentina. Arch Argent Pediatr 2006;104(4):295-300.

9. Paganini H, Della Latta MP, Muller Opet B, et al. Estudio multicéntrico sobre las infecciones pediátricas por Staphylococcus aureus meticilino-resistente provenientes de la comunidad en la Argentina. Arch Argent Pediatr 2008;106(5):397-403.

10. Egea AL, Gagetti P, Lamberghini R, et al. New patterns of methicillin-resistantStaphylococcus aureus (MRSA) clones, community-associated MRSA genotypes behave like healthcare-associated MRSA genotypes within hospitals, Argentina. Int J Med Microbiol 2014;304(8):1086-99.

11. Pérez G, Martiren S, Reijtman V, et al. Bacteriemia por Staphylococcus aureus adquirido en la comunidad en niños: estudio de cohorte 2010-2014. Arch Argent Pediatr 2016;114(6):508-13.

12. Berger-Bächi B. Expression of resistance to methicillin. Trends Microbiol. 1994;2(10):389-93.

13. Buckingham SC, McDougal LK, Cathey LD, et al. Emergence of community-associated methicillin-resistant Staphylococcus aureus at a Memphis, Tennessee Children's Hospital. Pediatr Infect Dis J 2004;23(4):619-24.

14. Boubaker K, Diebold P, Blanc DS, et al. Panton-valentine leukocidin and staphyloccoccal skin infections in schoolchildren. Emerg Infect Dis 2004;10(1):121-4.

15. McCaskill ML, Mason EO Jr, Kaplan SL, et al. Increase of the USA300 clone among community-acquired methicillinsusceptible Staphylococcus aureus causing invasive infections. Pediatr Infect Dis J 2007;26(12):1122-7.

16. Martínez-Aguilar G, Avalos-Mishaan A, Hulten K, et al. Community-acquired, methicillin-resistant and methicillinsusceptible Staphylococcus aureus musculoskeletal infections in children. Pediatr Infect Dis J 2004;23(8):701-6.

17. Bocchini CE, Hulten KG, Mason EO Jr, et al. PantonValentine leukocidin genes are associated with enhanced inflammatory response and local disease in acute hematogenous Staphylococcus aureus osteomyelitis in children. Pediatrics 2006;117(2):433-40.

18. Gillet $Y$, Vanhems P, Lina G, et al. Factors predicting mortality in necrotizing community-acquired pneumonia caused by Staphylococcus aureus containing PantonValentine leukocidin. Clin Infect Dis 2007;45(3):315-21.

19. Shallcross LJ, Fragaszy E, Johnson AM, et al. The role of the Panton-Valentine leucocidin toxin in staphylococcal disease: a systematic review and meta-analysis. Lancet Infect Dis 2013;13(1):43-54.

20. Comité Nacional de Infectología. Infecciones de piel y partes blandas en pediatría: consenso sobre diagnóstico y tratamiento. Arch Argent Pediatr 2014;112(1):e96-102.

21. Méndez Castellano H, M éndez M C. Sociedad y Estratificación: Método Graffar-Méndez Castellano. Caracas: FUNDACREDESA; 1994.

22. Comité Nacional de Crecimiento y Desarrollo. Guía para la evaluación del crecimiento físico. 3. ${ }^{a}$ ed. Buenos Aires: Sociedad Argentina de Pediatría; 2013.

23. Clinical and Laboratory Standards Institute. Performance Standards for Antimicrobial Susceptibility Testing; TwentyFive Informational Supplement (M100-S25). Wayne: CLSI; 2015. [Accessed on:August29th, 2017]. Availableat:http: / / www.facm.ucl.ac.be/intranet/CLSI/CLSI-2015-M100S25-original.pdf.

24. Harris A. Where did MRSA come from? [Accessed on: October 27th, 2016]. Available at: http:/ / www.uptodate. com/ contents / methicillin-resistant-staphylococcusaureus-mrsa-beyond-the-basics.

25. Paganini H, Della MP, Muller B, et al. Infecciones por Staphylococcus aureus resistente a meticilina adquirida en la comunidad en niños antes sanos y en niños relacionados al hospital en la Argentina. Rev Chilena Infectol 2009;26(5): 406-12.

26. Bogaert D, van Belkum A, Sluijter M, et al. Colonisation by Streptococcus pneumoniae and Staphylococcus aureus in healthy children. Lancet 2004;363(9424):1871-2.

27. Regev-Yochay G,Dagan R, RazM, etal.Association between carriage of Streptococcus pneumoniae and Staphylococcus aureus in children. JAMA. 2004;292(6):716-20.

28. Marcó del Pont J. Staphylococcus aureus de la comunidad, un problema reciente. Arch Argent Pediatr 2016;114(6):500-1.

29. WHO vaccine-preventable diseases: monitoring system. 2016 global summary. Coverage time series for Argentina. [Accessed on: April 6th, 2017]. Available at: http:/ / apps. who.int/immunization_monitoring/globalsummary / coverages? $\mathrm{c}=\mathrm{ARG}$.

30. Guillemot D, Bonacorsi S, Blanchard JS, et al. Amoxicillinclavulanate therapy increases childhood nasal colonization by methicillin-susceptible Staphylococcus aureus strains producing high levels of penicillinase. Antimicrob Agents Chemother 2004;48(12):4618-23.

31. Lawrence H, Nopper A.Skin and Soft-Tissue Infections. In: Long S, Pickering L, Prober C, eds. Principles and Practice of Pediatric Infectious Disease. $4^{\text {th }}$ ed. Philadelphia: Churchill Livingstone/Elsevier; 2012:427-35.

32. Martín Martín R, Sánchez Bayle M. Tabaquismo pasivo en la infancia y patología respiratoria de las vías bajas en una consulta de Atención Primaria. Rev Pediatr Aten Primaria 2009;11(44):587-95.

33. Fernández S, de Vedia L, López Furst MJ, et al. Methicillinresistant Staphylococcus aureus ST30-SCCmec IVc clone as the major cause of community-acquired invasiveinfections in Argentina. Infect Gen Evol 2013; 14:401-5.

34. Cobos-Carrascosa E, Soler-Palacin P, Nieves Larrosa M, etal. Staphylococcus aureus bacteremia in children: changes during eighteen years. Pediatr Infect Dis J 2015;34(12):1329-34.

35. Gonzalez BE, Martinez-Aguilar G, Hulten KG, et al. Severe staphylococcal sepsis in adolescents in the era of community-acquired methicillin-resistant Staphylococcus aureus. Pediatrics 2005;115(3):642-8 